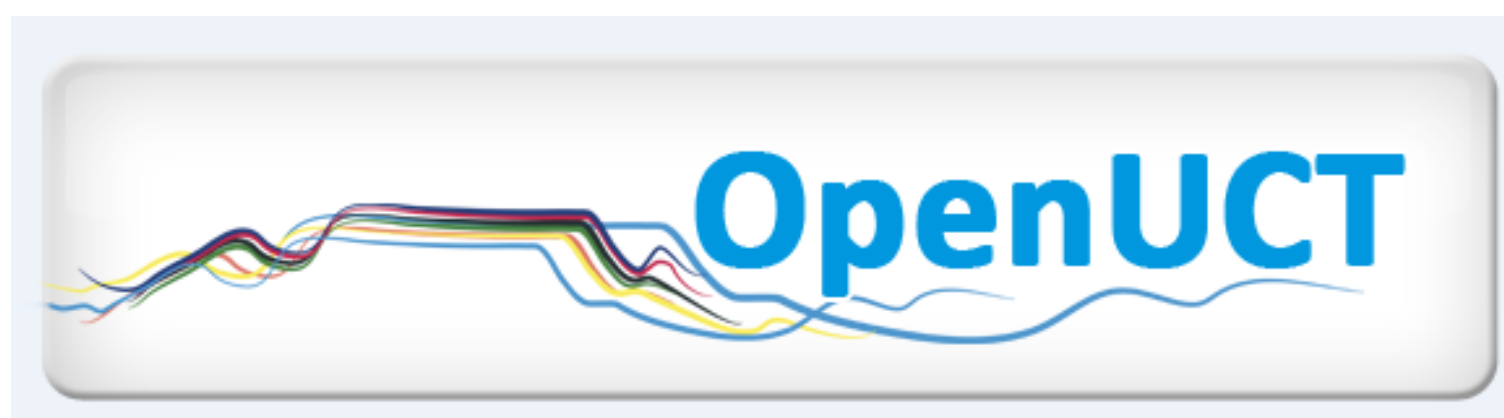

This is the post-print of De Jager, K. \& Brown, C. 2010. The tangled web: investigating academics' views of plagiarism at the University of Cape Town. Studies in Higher Education. 35(5): 513-528. DOI: 10.1080/03075070903222641.

It is made available according to the terms of agreement between the author and the journal, and in accordance with UCT's open access policy available:

http://www.openuct.uct.ac.za/sites/default/files/UCTOpenAccessPolicy.pdf, for the purposes of research, teaching and private study. 


\title{
The tangled web: investigating academics' views of plagiarism at the University of Cape Town
}

\author{
Karin de Jager* and Cheryl Brown \\ Centre for Higher Education Development, University of Cape Town, South Africa
}

${ }^{*}$ Corresponding author. Email: karin.dejager@uct.ac.za

\begin{abstract}
This article considers the problematic question of student plagiarism, its causes and manifestations and how it is addressed in academic environments. A literature survey was conducted to establish how higher education institutions approach these issues and a two-fold investigation was conducted at the University of Cape Town. Data was gathered from the case records of the university disciplinary tribunals dealing with plagiarism, and a survey was conducted among academic staff to establish how they dealt with issues surrounding plagiarism and academic dishonesty. Both qualitative and quantitative data was analyzed, from which it was established that academics might be unwilling to follow official university policies if they were perceived to be unrealistic.
\end{abstract}

Keywords: plagiarism; academic writing; writing skills; academic misconduct; academic literacies 


\section{The nature of plagiarism in the academic environment}

'Oh what a tangled web we weave,

When first we practice to deceive!' (Sir Walter Scot. Marmion, Canto vi, Stanza 17)

Academic institutions are seriously concerned with what they view as plagiarism among students. This article investigates the wide range of university approaches to the question and works from a basic assumption in that plagiarism at academic institutions is a complex issue that may involve a number of different behaviours ranging from deliberate academic dishonesty, to negligence, to ignorance of what plagiarism implies or the inability to deal with its requirements.

Plagiarism is traditionally regarded as an aspect of academic dishonesty or misconduct and penalties for being found guilty are usually severe. Typical penalties include fines, public reprimands, failing a course, obtaining zero marks, community service, suspension or expulsion from the university. Especially in the Internet age, where cutting and pasting have become very easy, students are often suspected of finding every available opportunity to cut corners and make use of writing that is not their own: 'after Google's launch in 1998 the Internet became a public elixir of information of increasingly dubious origin, seemingly meeting steadily rising student demand' (Mainka, Raeburn \& Earl 2006:13).

There are many definitions of plagiarism which usually include concepts such as the appropriation of others' words and ideas and presenting them as one's own without acknowledging the original source. The Oxford English Dictionary (2009) defines plagiarism as 'The action or practice of taking someone 
else's work, idea, etc., and passing it off as one's own; literary theft.' Definitions that do not use the concept of theft, nevertheless suggest misappropriation through statements such as 'the unacknowledged use of words and/or ideas of another' (Mainka, Raeburn \& Earl 2006:15) or 'presenting someone else's words or ideas as one's own, thus constituting misrepresentation and fraud' (Badke 2007:58). In the academic environment there is no doubt that plagiarism is regarded as a serious and punishable offence.

This legalistic and punitive approach to plagiarism is however also increasingly questioned by some academics who wish to emphasize that not all instances of plagiarism are equivalent and that treating every incident as academic misconduct is too simplistic; at the very least 'plagiarism is a grey area' (Tahir 2008) and should be seen in a more nuanced light. Many instances of what is commonly deemed plagiarism might not be deliberately dishonest, but could be the results of incompetence or ignorance.

To treat all instances of plagiarism as offences therefore, may be detrimental to the academic endeavour: 'One of the consequences of stating or implying that "all" plagiarism is "unacceptable" is that the default solution is necessarily a disciplinary rather than an educational one' (McGowan 2005:3). 


\section{Conflicting views of the importance of plagiarism}

A number of writers have noted the intensely emotional response of academics when encountering what they regard as plagiarism in their students' work. Williams, for example, notes 'a visceral sense of disappointment' and a feeling of betrayal of trust (2008:350) when she finds evidence of dishonesty in student work.

In a study of university students' perceptions of cheating and plagiarism, Ashworth, Bannister \& Thorne (1997) found that some students were 'perplexed as to why academic staff tend to be so uptight about this issue, especially in relation to undergraduate-level studies where students are generally not involved in producing original work but rather engaging with well-established ideas' (1997:200). Furthermore, the so-called 'mosaic technique' of putting together a paper 'entirely from disparate but suitably referenced sources, one's own input being only to thread the material together, was not seen as wrong...' (1997:201). In other words there seems to be a mismatch between teachers' perceptions of what is required in student writing on the one hand, and students' skills and understanding not only of plagiarism but also of the complexities of academic writing on the other.

\section{Plagiarism as a problem of academic literacy}

In mastering the practice of academic literacy, it is very important that students learn the language and the discourse of their particular subject(s). 'In 
terms of success at the university, written academic discourse is extremely important, as it is most often the way in which students (and academics) are judged and evaluated' (Angélil-Carter 2000:11). In students' attempts at practicing the discourse or trying out their own voices, they might then 'borrow' the voice or words of others to lend credence to their own.

Students from disadvantaged backgrounds who struggle with the demands of difficult subjects and/or with academic discourse in what may be a second or even a third language, find it particularly difficult to master academic literacy practices. A recent letter from a Turkish researcher in Nature expressed this predicament rather clearly: 'For those of us whose mother tongue is not English, using beautiful sentences from other studies on the same subject in our introductions is not unusual' (Yilmaz 2007).

In attempting to approximate the language of the discourse, students may resort to using sequences of words and even sentences from other writers, perhaps replacing odd words with synonyms or altering word order, but without quotation marks indicating where their own voices begin or end. They may also construct entire essays or assignments in this manner, by knitting together appropriate passages from a range of sources, using their own words only to provide the linking sentences. 
This practice, noted above as the 'mosaic technique' (Ashworth, Bannister \& Thorne 1997:201) and which Howard refers to as 'patchwriting' (1999), is unequivocally regarded as plagiarism in most academic environments, whether the passages are accompanied by references to the original sources or not. A number of writers, however (e.g. Howard 1999; Hall 2005) insist that patchwriting does not belong in the same league as cheating. 'These disenfranchised or "voiceless" students are not being dishonest; they are overly reliant on their sources because they have not discovered how to project "themselves" into their texts, and so they adopt various strategies for deferring to authority' (Hall 2005, §III. The student experience of plagiarism, para 10). They need to be taught how to express new and difficult concepts in their own words, not to be punished for trying to express themselves through the words of others.

Whether or not someone is guilty of an offence depends on intent and intent is a distinguishing feature in questions around plagiarism. Stubbings and Brine even classify plagiarism accordingly: reasons for student plagiarism 'tend to fall into the unintentional and intentional categories' (2003:1). It therefore seems particularly unreasonable that academic authorities are unwilling to take into consideration student intentions when attempting to distinguish between deliberate cheating and incompetence: 'the university sector appears to be reluctant to use the concept of "intent" to clarify the distinction between instances of plagiarism as an offence on one hand, and as a learning situation on the other' (McGowan 2005: 4). 
Intent, however seems a crucial aspect of the debate around what constitutes plagiarism. Howard, one of the strongest proponents of the theory of 'academic illiteracies,' asserts that if 'any evidence of unethical authorial intention' is absent, one is dealing with a problem of 'learning rather than cheating' (1999: xxii). She continues:

'This is not to advocate a 'more lenient attitude' toward plagiarism; rather, it is to enlarge the range of imagined motivations for textual practices traditionally labeled plagiarism, which in turn enlarges the range of appropriate responses, redefining and recategorizing the very word plagiarism.'

Although intent may in some cases be difficult to prove, 'there is no doubt that some plagiarism is accidental or inadvertent' (Park 2003:476). In many cases it is obvious that students do not intend to deceive when they use others' writing inappropriately, as may be illustrated by the fact that they cite sources for the words and ideas which they use as if they were their own.

\section{Institutional attitudes to plagiarism}

A number of studies have indicated that academic institutions do not necessarily act consistently in applying penalties for offences involving plagiarism (Tennant \& Duggan 2008:4) and that penalties for comparable offences may vary substantially. A major study in the UK found that a considerable number of higher 
education institutions were not advising their academics which penalties would be most suitable in cases dealing with plagiarism (JISC 2007:1).

A reason might be that institutions often do not define very explicitly what they mean by plagiarism and do not prescribe nuanced approaches to dealing with its manifestations. Academics too, seem to concentrate on finding and dealing with offenders, rather than considering their difficulties as aspects of teaching and learning: '.. academics' interests tend to be very focused on knowing how much is happening and how best to catch those doing it without expending too much of their own time and energy' (Macdonald \& Carroll 2006:234). Students are often expected to inform themselves about plagiarism, for example by reading handouts or web sources. Institutional web sites that deal with these issues 'concentrate on informing students as to what plagiarism is, that it is bad and how they will be punished if they do it' (Macdonald \& Carroll 2006:234).

In response to similar findings, a number of authors including Park (2003, 2004), JISC (2005) and Macdonald \& Carroll (2006) have been calling for institution-wide guidelines and holistic approaches that would clearly spell out definitions and provide procedures for dealing with plagiarism, at the same time providing students with support structures and skills to manage their learning in the academic environment without having to resort to dubious practices: 
An institutional approach to dealing with plagiarism by students should set plagiarism clearly into the context as a breach of academic integrity, frame it as inappropriate and unacceptable behavior rather than criminalizing it, embed it into academic rules and regulations and promote it throughout the institution (Park 2004:294).

Although such an institutional and holistic approach is not simple to implement, Park (2003:483) makes it clear that institutional quality may be compromised by inadequate approaches to dealing with plagiarism and that appropriate teaching and learning strategies should be in place, together with 'cohesive frameworks ... that are based on prevention supported by robust detection and penalty systems that are transparent and applied consistently' (2003:483-4). Key components of such a framework, according to Park (2004:294) are that the responsibilities of different players (i.e. the institution, its academic staff and its students) should be clearly specified, that procedures should be spelled out unambiguously, and that penalties should be applied uniformly and transparently (2004:294).

\section{Plagiarism in the United Kingdom}

In May 2008 the Higher Education Academy in the United Kingdom published the second part of its country-wide Academic Misconduct Benchmarking Research Project: The recorded incidence of student plagiarism and the penalties applied (Tennant \& Duggan 2008). This work sought to establish the kinds of penalties that UK institutions applied and presents findings from a survey of the higher education institutions in the UK. 
The study found 9229 cases of plagiarism reported by 93 institutions in a given year (Tennant \& Duggan 2008:8). This was the equivalent of 7.2 formally recorded cases of plagiarism per 1000 students, although there was considerable variance between different institutions, ranging from 3.1 cases 13.7 cases per 1000 students (2008:9). The group of institutions that recorded the lowest rates of plagiarism, was the group of the smaller institutions with low incomes, while the larger institutions with greater proportions of postgraduate students and larger incomes, recorded proportionally more and also stricter penalties (2008:19). Full time and part time students were counted separately (2008:8-9).

\section{Dealing with plagiarism at the University of Cape Town}

The University of Cape Town, as at many other universities both in South Africa and abroad, is seriously concerned about academic dishonesty and plagiarism among students and reacts very strictly to students who are accused of plagiarism. Its websites are clear that committing plagiarism is treated as a major breach of University rules which will be dealt with by a disciplinary tribunal:

\footnotetext{
'Penalties imposed by the tribunal range from expulsion from the university, for serious misconduct such as plagiarism and violence, to reprimand for the less serious cases.' (http://www.uct.ac.za/students/postgraduates/discipline/ and http://www.uct.ac.za/students/undergraduates/discipline/)
} 
The University of Cape Town, like many other institutions of higher education as noted above, regards plagiarism primarily in terms of theft:

\footnotetext{
'It does not matter how much of the other person's work you use (whether it is one sentence or a whole section), or whether you do it intentionally or on purpose; if you present the work as your own without acknowledging that person, you are committing theft.' (Avoiding plagiarism: a guide for students.

http://www.uct.ac.za/downloads/uct.ac.za/about/policies/plagiarism_students.pdf)
}

As in many academic institutions (Ashworth, Bannister \& Thorne 1997:188) students are required to submit a signed statement with every significant piece of written work declaring that they understand what plagiarism is, that the work being handed in is their own, that all sources have been credited and that they have not allowed anyone else to copy their work.

In addition to demanding this signed statement, the University of Cape Town has purchased a site licence for Turnitin software which automatically checks student projects for originality and which is intended to function both as a deterrent to plagiarism and as a means of determining unattributed copying or cutting and pasting. It is however often stated informally among academic staff that these measures are inadequate and that students persist in copying, cutting and pasting in spite of knowing that serious disciplinary consequences may result from being found out. 
Institutional policies that have bearing on issues of plagiarism are gathered on the university web site at http://www.uct.ac.za/about/policies/. These are brief documents providing guidance to committees of assessors and other examining bodies, to staff and to students on what constitutes plagiarism and how it should be treated. According to the guide on process for staff members, there is little space for individual decision making. The examiner or head of department has to decide whether plagiarism is evident and 'must allocate zero for the assignment.' Then, 'where plagiarism is found or suspected ... the Head of Department must refer the matter to the Vice-Chancellor's nominee for possible disciplinary action' (emphasis added).

Only at this point in the procedure will attention be paid to whether academic problems such as inadequate referencing, or actual cheating are at stake and whether or not to continue with the prosecution. The policy guide for students gives more detail on what constitutes plagiarism and notes that assistance may be provided by Library Staff or the Writing Centre, but here too, the main emphasis seems to be on punishment:

By committing plagiarism you will get zero for the plagiarized work, and may fail the course. In addition, the matter must be referred to the Vice-Chancellor or nominee for possible disciplinary action ... If this is the case, and the plagiarism is substantial ... the prosecution will ask for your expulsion. Even if you are not expelled, a conviction for cheating on your academic record is likely to limit your career opportunities...(Avoiding plagiarism: a guide for students.

http://www.uct.ac.za/downloads/uct.ac.za/about/policies/plagiarism_students.pdf) 
These strict official injunctions on the one hand and many informal reports of both dishonest practices and serious problems with writing and citing among students at the University of Cape Town provided the impetus for this investigation.

\section{Methodology}

Data was gathered from two sources:

1. Lists of Student Disciplinary Tribunal hearings held between 2005-2007 were obtained from the Legal Counsellor in the Office of the Registrar who is responsible for the tribunal administration.

2. An online survey instrument was developed and mounted on a web database which was delivered to the email addresses of full time academic staff that had been in the employ of the University at least since 2005. Responses were entered directly into the database and were recorded anonymously, so that respondents were at no time identifiable from their responses.

A list of full time academic staff members who had been employed since 2005, was obtained from the Human Resources department and matched with their current email addresses by Information \& Communication Technology Services. The instrument was pilot tested by a few members of staff who did not then participate in the final survey and was submitted to the Centre for Higher 
Education Ethics Committee for clearance. The investigation was conducted during May 2008.

The survey instrument was constructed to explore the issues around plagiarism ranging from outright dishonesty to various manifestations of ignorance at the University of Cape Town. One of the authors had been gathering evidence on the prevalence of plagiarism for a number of years in her capacity as a citation and referencing advisor at this institution. The instrument was designed to elicit responses about perceptions of plagiarism and its prevalence among students. These issues were addressed both quantitatively, by soliciting responses from a closed range of possible answers, as well as qualitatively, by leaving spaces for individual responses to open ended questions.

Quantitative data was analysed using Excel Pivot Tables and the open ended responses to the survey were exported from Excel into N/Vivo text analysing software. The coding was initially done by one author reading through each response individually and assigning free nodes based on the general theme of the comment. These were then further grouped into tree nodes using common themes which emerged. A report of the output was generated and the other author scrutinised the responses to validate and clarify the coding. After discussion some of the categories and codes were redefined. Initially each open ended question was analysed separately. As the coding progressed, a 
framework for categorising the qualitative data begun to emerge. Comments and concerns focused around three main themes and several sub themes were identified within each main theme. The main themes were educational issues, University policies and punishment, and other concerns among staff, and will be discussed below.

The original mailing list contained 802 names from which the names of the persons who had participated in the pilot survey, and the names of (four) people who had indicated that they were not able to complete the survey, were removed, leaving a total of 788 names to whom the survey was sent. After three follow-up reminders, a total of 199 responses of which 191 were usable, were received, giving a response rate of $24 \%$.

It is recognized that the response rate was low, but such low response rates are an increasingly common feature of electronic mail surveys over the past 1520 years. In 2001 Sheehan noted a decline in mean response rates for surveys conducted by email over the past 15 years from $61 \%$ to $24 \%$ and academics are particularly noted for being very poor survey respondents (Mitchell 1998). A meta analysis of 199 surveys conducted online showed that half of the surveys got a response rate of at least $26 \%$ (Hamilton 2003), which leads the authors to propose that the present response rate provided us with results that fall within a range of acceptability. 
A further reason for the low response rate might have been be the subject of the survey itself. Mainka \& Raeburn had found in an investigation of staff perceptions of academic misconduct, that the majority of staff who did not respond to the survey 'still remain the disengaged and largely under-investigated proportion of academics' (2006:9). This could suggest that, in addition to being poor respondents, academics at the University of Cape Town who replied were those most concerned with plagiarism, but that here too, many might not be particularly interested.

\section{Findings from the Disciplinary Tribunals}

Data obtained from the official Disciplinary Tribunal case reports for 2005 - 2007 revealed that between $51-89$ cases relating to academic dishonesty were dealt with each year, as shown in the table below. As the head count of student numbers were 21942 in 2005, 21454 in 2006 and 21419 in 2007, the recorded instances of plagiarism at may be calculated to have been 4.1 per 1000 students in 2005, 2.4 in 2006 and 3.5 in 2007. Head count was used instead of full time equivalent numbers for this comparison, as the UK study counted full time and part time students separately; effectively a head-count.

In comparing these figures with those from the UK, it is clear that 2006 had a lower rate of recorded plagiarism than in any single year recorded by the UK universities where the group with the lowest recorded rates of plagiarism ranged between 3.1 - 7 per 1000 students (Tennant \& Duggan, 2008:9). The 
rates of other two years, i.e. 4.1 per 1000 students in 2005 and 3.5 per 1000 in 2007 fall barely within the range recorded by the group of smaller, lower income UK universities that have fewer postgraduate students and which recorded the lowest rates of plagiarism as was discussed above.

Table 1 shows that the majority of cases seem to have dealt with issues relating to cheating such as copying and cut-and-pasting rather than incompetence, such as 'inadequate referencing.'

Table 1 Classification of cases

\begin{tabular}{|l|r|r|r|}
\hline Classification of cases & 2005 & 2006 & 2007 \\
\hline Internet Plagiarism & 10 & 20 & 26 \\
\hline Exam dishonesty & 9 & 7 & 3 \\
\hline Copying & 54 & 18 & 27 \\
\hline Allowing copying & & 3 & 2 \\
\hline Inadequate referencing & 7 & 1 & 4 \\
\hline Exchanging MatLab codes & 4 & 2 & \\
\hline Academic dishonesty & 5 & & 13 \\
\hline Unspecified plagiarism & $\mathbf{8 9}$ & $\mathbf{5 1}$ & $\mathbf{7 5}$ \\
\hline TOTAL & & & \\
\hline
\end{tabular}




\section{Findings from the Survey to academics}

Issues relating to assignments for courses taught at the University of

\section{Cape Town}

The first question sought to explore the perceptions of academics about the extent to which students were engaging in practices that might broadly be seen to encompass 'plagiarism' both as cheating and as incompetence. Academics were asked whether they had seen or become aware of any of the following practices since 2005:

1. Assignments or essays where substantial parts of the text were downloaded from the web.

2. Assignments or essays where substantial parts of the text were copied down from a printed source.

3. An assignment or essay that had previously or simultaneously also been submitted for another course by the same student.

4. An assignment or essay that had previously or simultaneously been submitted for another course by a different student.

5. Two or more students claiming to have handed in their own work, but where identical or very similar answers strongly suggest that copying has taken place.

6. Passages copied or cut-and-pasted into academic assignments without any sources being cited.

7. Passages where sources are cited, but where an absence of quotation marks makes it impossible to tell where quotations begin or end and which are the student's own words.

8. Quotations and/or citations 'lifted' from other works in such a way that they seem to have been taken from the original rather than from the intermediate resource (i.e. the original, quoted resource not consulted. 
Questions 3-5 enquired about practices that are generally understood to reflect academic dishonesty relating to copying or misusing the work of others. Questions 1-2 and 6-8 enquired about practices that are generally regarded as plagiarism, but which may also represent the 'grey areas' where it is necessary to look at offending work more closely to establish whether evidence of intention to cheat was discernible, or whether ignorance or incompetence seemed to be the cause. A ninth question had also been asked about dishonesty in using 'Matlab,' a programming language widely used in science teaching. Undergraduate students had copied others' code in class tests. Switching codes had been recorded as offences in disciplinary tribunals between 2005 and 2006 . Only eight instances of such code switching were reported in the survey, and a total of six were recorded by the disciplinary tribunals.

A total of 782 positive responses were received for these questions. Of them, 200 are indicative of cheating (questions 3,4,5,9) and the rest (582) represent that grey area where at least a possibility exists of intention not to cheat, but that ignorance or incompetence were involved and that the issues at stake could be pedagogical rather than disciplinary. The results are illustrated in Figure 1.

Figure 1 begins to provide evidence that students are perceived to be struggling as well as cheating. The most frequently encountered problem (yes=144) seems to involve 'patchwriting' where students cite sources, but an absence of quotation marks makes it impossible to tell where quotations or own 
words begin or end. The second highest score (yes=139) was for copying without citing sources, possibly but not certainly with the intention of cheating. The next highest scores were very close. Question 5 (yes=123), two or more students copying work from one another does reflect cheating, and question 8 (yes=121) using others' quotations represents a grey area reflecting either incompetence, ignorance of correct citation practice, or the intention to cheat.

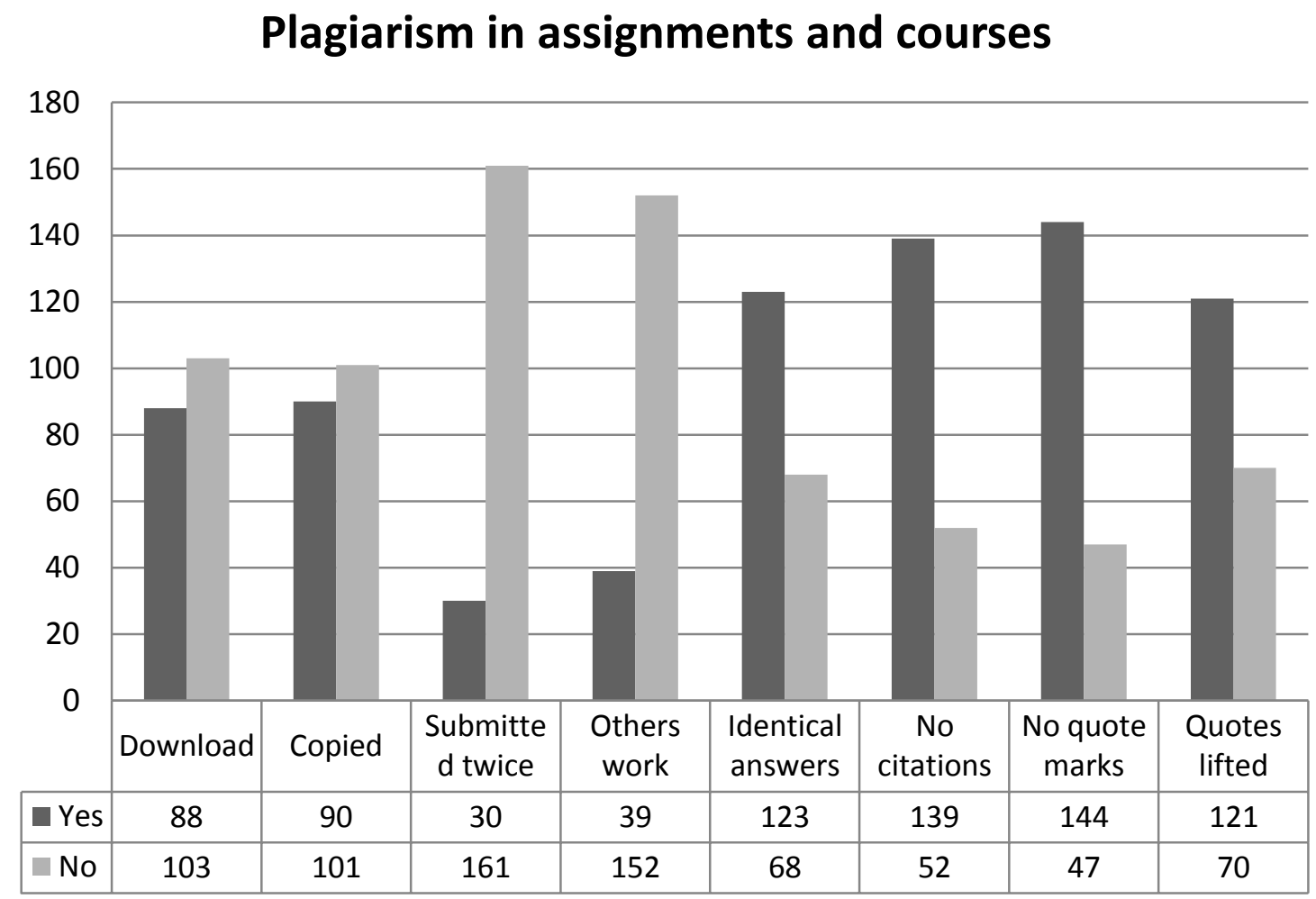

Figure 1. Plagiarism in Assignments and Courses

Comparing Figure 1 above with Table 1 that illustrated the cases recorded by the disciplinary tribunals, it becomes obvious that many instances of plagiarism are not being reported to the disciplinary tribunals. Over three years, a 
total of only 12 cases of 'inadequate referencing' had reached the tribunals, but the highest incidences of plagiarism reported by academics in this study concerned 'no quotation marks' (144) or 'no citations' (139) which unquestionably are examples of inadequate referencing techniques.

\section{Issues relating to examinations at the University of Cape Town}

It was clear from responses to this section that not very many academics report experiences of cheating during examinations, although this is one of the issues that features in the hearings of the disciplinary tribunals. The most frequently observed form of cheating in examinations was either trying to communicate with others (39 responses) or bringing hidden notes to the examination venue (37 responses).

\section{Issues relating to the use of Turnitin}

The University of Cape Town has a license for the use of the web-based Turnitin tool on campus, which produces 'originality reports' on student papers, but does not distinguish between proper citation and dishonest copying. It is available through the Virtual Learning Environment, so that students themselves are able to submit their written work. Lecturers or tutors then have to consider the originality reports to decide whether passages that are marked as not original constitute dishonest copying. 
The intention was to establish whether academics make substantial use of the tool and 33 of the 191 respondents replied that they required students to submit work to Turnintin, while a further 18 said that the 'sometimes' did; thus indicating that 140 respondents were not using the software.

Table 2. Reasons for not using Turnitin

\begin{tabular}{|l|l|}
\hline Reasons for not using Turnitin & \\
\hline I don't know about Turnitin at UCT & 34 \\
\hline I don't know how to submit work to Turnitin & 28 \\
\hline I don't like using software to catch students out & 3 \\
\hline I don't need to use Turnitin & 34 \\
\hline Other & 40 \\
\hline Blank & 52 \\
\hline
\end{tabular}

A further question enquired whether those that used Turnitin had indeed been able to find instances of academic dishonesty in student work of which they would otherwise have remained unaware. Here 50 responses were received of which only 12 said 'no,' indicating that when it was used, it was found to be effective. The results are illustrated in Table 2.

Respondents who selected 'Other' were asked to explain. Responses seemed to suggest that both ignorance and apathy among staff were dominant reasons although some thought it would be too difficult or too time-consuming to use. Additional reasons for not using Turnitin included that the nature of the 
courses taught, e.g. using graphs, equations, maps, programmes or circuits made Turnitin unsuitable, or that staff were too busy to learn to use it.

\section{Dealing with academic dishonesty}

When asked whether respondents had actually encountered instances of what they regarded as academic dishonesty, 140 replied that they had and 51 that they had not. Those that had, were asked to indicate how they responded in each of the following situations, by indicating 'never,' 'sometimes' or 'always.'

The options were:

1. Failed the assignment/paper on account of plagiarism

2. Gave the assignment zero marks on account of plagiarism

3. Discussed the matter with the Head of Department for a decision

4. Discussed the matter with the student and required that the assignment be rewritten with all instances of plagiarism removed

5. Discussed the matter with the student, but took no further action

6. Did not know what to do, so ignored it and took no further action

7. Referred the student to the Writing Centre or the Library to be taught proper citation conventions

8. Referred the student to the university disciplinary tribunal on account of plagiarism.

Responses show that many staff tend not to send students to the disciplinary tribunals, but that they seem to prefer dealing with it themselves, or in consultation with their Head of Department. Figure 2 illustrates responses 'always' and 'sometimes' added together to show how respondents reacted at least some of the time. 


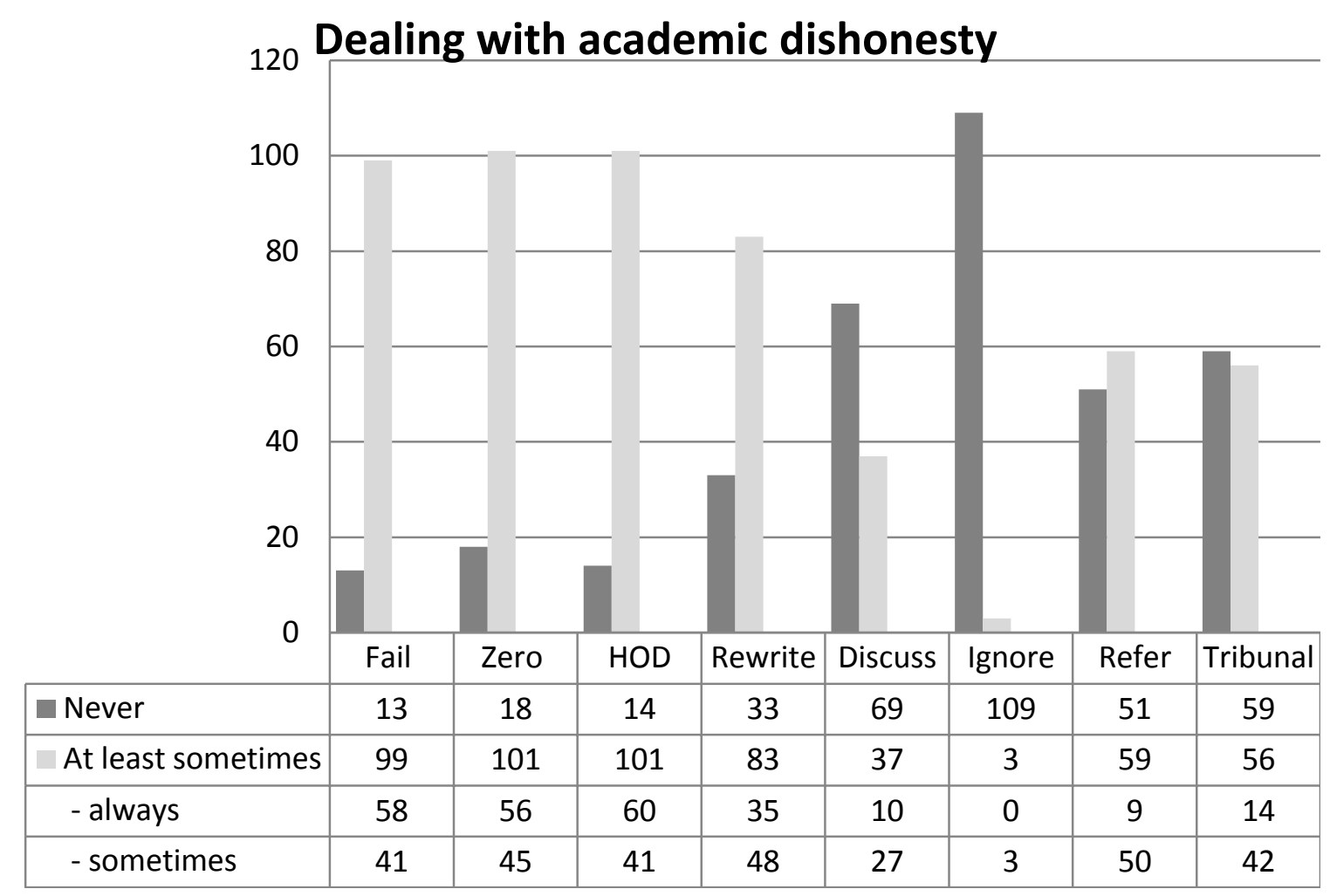

Figure 2. Dealing with Academic Dishonesty

The figure 2 shows that academics only rarely completely ignore what they regard as plagiarism, but that they are much more inclined to fail the assignment, or to assign zero marks, or to approach their Head of Department for a decision, or somewhat less frequently to require that the assignment be rewritten. The numbers of respondents who have never referred a matter of plagiarism to a disciplinary tribunal, contrasts sharply with the number who say that the never ignore incidents of plagiarism completely. Only 56 have referred students to a tribunal at least sometimes, but 109 never ignore plagiarism completely. This confirms that a significant number of incidences of what academics regard as plagiarism, never reaches the tribunals. 
The last question in this section asked for free-text comments on any other ways in which respondents have dealt with plagiarism and produced a total of 39 , which confirmed the dual nature of what respondents regarded as plagiarism. Ten stated that the problem was frequently pedagogical rather than disciplinary, but nine referred to aspects of academic dishonesty, using words such as 'cheating,' 'stealing,' 'crib notes' or copying. Of these, six specifically mentioned the university tribunal or court. Six of the respondents emphasized that they did not always treat what they regarded as plagiarism in the same way, but would vary the responses or penalties according to what they regarded as the severity of the offence. Examples:

'Depending on severity, either talk to student and penalise, give $0 \%$, or send to tribunal.'

'I always treat each case on it own merits and according to gravity. Therefore the student may be failed outright or maybe asked to rewrite the offending sections.'

\section{Issues particularly emphasized}

A salient feature of the responses had been the number and the intensity of the free text responses and it was clear that many of the respondents had engaged very seriously with the survey. A total of 121 (out of the original 191) respondents had made 284 full text comments throughout the questionnaire, confirming the position of Ashworth, Bannister and Thorne (1997) and others (e.g. Williams 2008), that plagiarism in higher education often is an intensely 
emotional issue among academic staff. The style of language used also demonstrated how strongly respondents felt about the issue, with the majority of respondents using modal auxiliary verbs that indicate a strong commitment to the issues they highlight. For example:

\footnotetext{
'Plagiarism (provided it is properly explained) must be treated and punished exactly the same as any other dishonesty'

'Posters should be put up in all departments showing an example of a transcript containing a plagiarism record'

'I am absolutely certain that the academic dishonesty I have encountered was conscious and deliberate dishonesty. Students are fully aware when they are plagiarizing and are generally trying to take advantage of perceived grey areas'

In the final section of the questionnaire, respondents were asked to
} propose other kinds of online resources or different strategies to assist in dealing with plagiarism; or to make any further comments about academic dishonesty. Responses frequently overlapped, restated or emphasized points already made. Many comments were quite lengthy and discussed more than one issue. Out of the total of 119 comments from 80 respondents, 104 substantive issues were discerned. These responses clustered around three main areas of concern: educational issues around teaching and learning (52); university issues around policies and discipline; (36) and other staff concerns (16). 


\section{Educational issues}

A total of 52 comments could be identified and consisted of issues, suggestions or proposed solutions in the educational rather than the disciplinary domain. They were broadly divisible into the need for:

a. $\quad$ Better teaching and training in writing skills (20 comments).

The most important call was for increased support for academic writing; that students should be taught to understand plagiarism better; that writing and referencing are difficult for many students and that teaching strategies should be adapted so that it is more difficult if not impossible to plagiarise. Examples:

'I take most acts of academic dishonesty as a sign that we have failed to educate the students'

'... they don't need to be taught about avoiding plagiarism, they need to be taught about writing'

'... students who are under prepared do not understand what a lit review is and find it very difficult to paraphrase information, never mind integrate information from different sources'

b. $\quad$ Adapting teaching strategies to combat plagiarism (20 comments).

It was recommended that academic staff should take greater responsibility for adapting their teaching strategies so that class work doesn't count for too much. 
In large classes, tutors were seen as a problem and they too, should be better informed. Examples:

'While some departments and lecturers continue to set assignments, tests and exams that require recall of information rather than demonstration of ability to analyse and to explicate, we will continue to be faced with this kind of problem.'

' ... many students will cheat if they feel they can get away with it ... Problems ..stem from ... a reliance on tutors to help mark tests and projects. The tutors have been a particular problem. For the last two years certain of them have effectively encouraged cheating...

c. Changing students' attitude to issues of ethics and academic integrity (12 comments).

While it was noted that dishonesty still is the exception rather than the norm, staff believed that student awareness of ethical issues should be improved, that students don't take plagiarism seriously and that it is unfair to the honest ones when others get away with plagiarism. Examples:

'I am more concerned about making sure students understand the ethics involved rather than the mechanics of the matter.'

'lecture students on academic integrity issues so that they understand what constitutes improper conduct and why it is wrong.'

'Honest students are sick of the way that some students get away with stuff here at UCT.' 


\section{University policies and punishment}

A total of 36 comments were received and could be divided into the following sections:

\section{a. University inconsistency}

Responses (20) echoed concerns raised in the literature and centered around perceptions that policies on plagiarism were problematic, inconsistent or not clear enough. Respondents were of the opinion that departmental approaches varied and that the current system was not functioning as a sufficient deterrent. Examples of comments:

'My general perception of the processes to deal with academic dishonesty at UCT is that they are random and vague. The process lacks consistency and transparency.'

'The university should develop and adopt a common understanding of academic dishonesty and plagiarism in particular that applies across the whole campus community;'

'Treatment of plagiarism by staff is inconsistent both within and between departments.'

b. Punishment

It was noted above that the majority of respondents wished to deal with plagiarism through better teaching and learning strategies. Another 16 responses however, took the opposite position and emphasized the need for stronger 
punitive measures, e.g. to refuse 'Duly Performed' certificates (which qualify students to write an examination), or to give zero marks; or called for keeping a university-wide register of students found guilty of plagiarism. Examples:

'Stronger disciplinary measures [are required] - the reports from the registrar posted on notice boards will not convince anyone not to cheat.'

'I think the penalties should be greater. We never expel - the expulsion is always suspended, no matter how severe the academic dishonesty.'

Although it was noted above that official policies relating to plagiarism do seem strict and severe, responses to this survey have confirmed that in practice the policies are frequently disregarded. Cases of perceived plagiarism are often not referred to the disciplinary tribunals and members of staff deal with what they regard as plagiarism and academic dishonesty according to their own perceptions of what is required.

\section{Concerns among staff}

Sixteen comments were received. One substantively new issue emerged: eleven respondents in this section (some rather emphatically) noted that academic dishonesty (including inappropriate co-authorship) was a problem among academic staff as well. Examples:

' ... any attempts at stamping out undergraduate plagiarism are bound to fail unless staff plagiarism is first stamped out' 
'Faculty are ALSO guilty of plagiarism - in research, in teaching, and in conference papers. I do not say this lightly.'

'It is quite amazing that whilst UCT correctly emphasizes undergraduate plagiarism, it turns a blind eye to staff and postgraduate plagiarism in the form of undeserved coauthorship of publications.'

The literature too, seems to emphasize that plagiarism among academic staff is not frequently discussed or explored. 'No one actually knows the true scale of plagiarism among academics' states Shepherd (2007) in a newspaper article that broaches this difficult subject. She notes that while universities may be eager to root out plagiarism among students, they are interested in boosting publication output and might turn a blind eye to dubious practices among staff.

Academics were also concerned about the additional workload required for dealing effectively with plagiarism and academic dishonesty. Five responses noted that dealing with it is 'very time-consuming', 'wastes an enormous amount of time' or even 'takes too much energy.' Similar concerns were also noted in the literature (Mainka \& Raeburn, 2006:9; Macdonald \& Carroll,2006: 234).

\section{Discussion}

Comparing the results of the Disciplinary Tribunal records with figures produced in the UK, a disproportionately low rate of referral seems to be evident. At the University of Cape Town between $2.4-4.1$ per 1000 students were involved in disciplinary cases dealing with plagiarism, while the range in the UK 
was between $3.1-13.7$ cases per 1000 students. As it has however also been shown that cases of plagiarism seem to be significantly underreported at the University of Cape Town, the range is probably comparable to the lower ranges in the UK.

It was also shown that the bigger, better resourced institutions with larger proportions of postgraduate students had the highest numbers of cases reported in the UK. It may therefore be a cause for concern that the University of Cape Town, which also positions itself as a research university, has such a low rate of reporting incidents of academic dishonesty, which in turn might support a minority staff opinion that some students 'get away with' academic dishonesty.

This study has shown that plagiarism is regarded as a serious but contested issue at the University of Cape Town. Staff views of what constitutes plagiarism do reflect the nuances that are found in the literature, although some respondents (the majority) preferred to view it in the light of issues to do with inadequate academic literacy. The others saw it as a problem of academic dishonesty and were concerned that processes and policies for dealing with dishonesty were inadequate; that stricter punitive measures were required. At the same time however, staff seem to be more reluctant than in the UK to refer students to the university authorities for disciplinary action. In exploring how staff dealt with incidents of dishonesty the most common response was that they dealt 
with it themselves or internally within their departments as opposed to referrals to the official disciplinary tribunals.

Qualitative comments frequently focused on educational issues, with staff calling for better teaching and training in writing skills, greater responsibility by lecturers, and concerted efforts to change student attitudes to ethics and academic integrity. What was perceived as the University-wide lack of consistency in applying the rules was noted as a problem, as was the increased workload required at the individual level to deal with these issues.

Unsolicited comments on being witness to academic dishonesty among lecturers themselves, were noted. Although there were not many, the emphasis and concern with which they were voiced, leads one to conclude that this might be a hitherto unaddressed problem at the University of Cape Town.

\section{Conclusion}

This study has found evidence of considerable concern and engagement among academic staff with issues of what they view as plagiarism, but also a lack of agreement on the main issues and inconsistency in dealing with them. It has confirmed that both the incidence and the approaches to dealing with the problem are not markedly different from approaches reported in the literature from the UK \& USA, although a few new emphases have emerged. 
Perhaps most importantly, the study has shown that academics tend to evade official university policies and procedures if they do not perceive these policies to be sufficiently sensitive to individual interpretation. This in turn might have the unfortunate implication that if policies are seen to be ignored, perceptions arise that some students who might really be guilty of punishable offences, are not held accountable.

A further issue that does not seem to be discussed in the literature of student plagiarism, is that the problem is not limited to undergraduate students only, but that some members of staff were very concerned about what they perceived as plagiarism among postgraduates and their fellow academics. This is a serious issue which requires further exploration.

\section{References}

Angélil-Carter, S. 2000. Stolen language: Plagiarism in writing. Harlow: Longman.

Ashworth, P., Bannister, P. \& Thorne, P. 1997. Guilty in whose eyes? University students' perceptions of cheating and plagiarism in academic work and assessment. Studies in Higher Education, 22, no. 2:187- 203.

Badke, William.2007. Give plagiarism the weight it deserves. Online, 31, no. 5: 58- 60. 
Hall, J. 2005. Plagiarism across the curriculum: how academic communities can meet the challenge of the undocumented writer. Across the Disciplines: Interdisciplinary Perspectives on Language, Learning and Academic Writing. http://wac.colostate.edu/atd/articles/hall2005.cfm

Hamilton, M.B. 2003 Online Survey Response Rates and Times. http://www.supersurvey.com/papers/supersurvey_white_paper_response_rates.pdf Howard, R.M. 1999. Standing in the Shadow of Giants: Plagiarists, Authors, Collaborators. Stamford, Conn.: Ablex.

JISC. 2005. Deterring, detecting and dealing with student plagiarism. http://www.jisc.ac.uk/media/documents/publications/plagiarismbp.pdf JISC. 2007. New JISCPAS research reveals vast variations in penalties for plagiarism. http://www.jisc.ac.uk/news/stories/2007/06/news_amber.aspx

Mainka, C. \& Raeburn, S. 2006. Investigating staff perceptions of academic misconduct: first results in one school. $2^{\text {nd }}$ International Plagiarism Conference 2006: Proceedings. Newcastle: Northumbria Learning Press. 1-15. http://plagiarismadvice.com/documents/papers/2006Papers19.pdf 
Mainka, C., Raeburn, S. \& Earl, S. 2006. A UK institution's university-wide approach to plagiarism: first results and recommendations. International Journal for Educational Integrity, 2, no. 1:13-25.

http://www.ojs.unisa.edu.au/index.php/IJEl/article/viewFile/27/16

Macdonald, R. \& Carroll, J. 2006. Plagiarism - a complex issue requiring a holistic institutional approach. Assessment \& Evaluation in Higher Education. 31, no. 2: 233-245.

McGowan, U. 2005. Educational integrity: a strategic approach to anti-plagiarism. 2nd Asia-Pacific Educational Integrity Conference, University of Newcastle, Australia: 1-9.

http://www.newcastle.edu.au/conference/apeic/papers pdf/mcgowan 0548 edd.pdf

Mitchell, V-W. 1998, Improving mail survey responses from UK academics:

Some empirical findings. Assessment \& Evaluation in Higher Education. 23, no. 1: 59-71.

Oxford English Dictionary. 2009. Plagiarism. http://www.oed.com.

Park, C. 2003. In other (people's) words: plagiarism by university students literature and lessons. Assessment \& Evaluation in Higher Education, 28, no. $5: 471-488$. 
Park, C. 2004. Rebels without a clause: towards an institutional framework for dealing with plagiarism by students. Journal of Further and Higher Education. 28, no. 3:291-306.

Sheehan, K.B. 2001. E-mail Survey Response Rates: A Review. Journal of Computer Mediated Communication 6, no. 2.

http://jcmc.indiana.edu/vol6/issue2/sheehan.html

Shepherd, J. 2007. When plagiarism is academic. The Guardian. 30 October 2007. Education news \& features section, p.10.

http://www.guardian.co.uk/education/2007/oct/30/highereducation.uk

Stubbings, R. \& Brine, A. 2003. Plagiarism and the role of the library. Library \& Information Update. December 2003.

http://www.cilip.org.uk/publications/updatemagazine/archive/archive2003/decem ber/update0312c.htm

Tahir, T. 2008. Cleaning up the act. Times Higher Education, 28 August.

Tennant, P. \& Duggan, F. 2008. The recorded incidence of student plagiarism and the penalties applied. Academic Misconduct Benchmarking Research Project: Part 2. JISC PAS. Newcastle: The Higher Education Academy. 
Williams, B.T. 2008. Trust, betrayal, and authorship: plagiarism and how we perceive students. Journal of Adolescent \& Adult Literacy, 51, no. 4:350-354.

Yilmaz, I. 2007. Plagiarism? No, we're just borrowing better English.

Correspondence. Nature. 449:658 (October).

$[7,417$ words $]$ 